\title{
Drying models to estimate moisture change in switchgrass and corn stover based on weather conditions and swath density
}

\author{
Abstract. \\ An environmental chamber was built to evaluate the effect of weather parameters and swath \\ density that affect the drying rate of crops during field drying. A series of 52 drying experiments \\ were conducted on corn stover (CS) of which 27 were used for model development and 25 were \\ used for model validation. Similarly, 80 experiments were performed on switchgrass of which 72 \\ were used for model development and eight were used for model validation. Regression models \\ were developed for switchgrass and CS that predicted the drying rate based on environmental \\ conditions and swath density. During the day, radiation was found to be the most significant \\ variable that affected the drying rate of switchgrass with a correlation coefficient ( $r$ ) of 0.5 and \\ 0.49 during different maturity stages. During the night, VPD was the most significant variable \\ that affected the drying rate with $r$ of 0.69 for corn stover (CS) and 0.83 to 0.85 for switchgrass. \\ The effect of wind speed was variable and was found to be dependent on solar radiation. During \\ the day time, an increase in wind speed removed the heat produced by radiation and thus \\ decreased the drying rate. However, at night, the wind speed was positively correlated with \\ drying rate. Swath density was negatively correlated $(r=-0.38)$ with the drying rate of \\ switchgrass which suggested that biomass should be dried in wide swaths if possible. The model \\ should be a useful tool for planning field logistics and transportation operations for biomass \\ supply.
}

Keywords. Drying rate, biomass, weather conditions, swath density, empirical model, harvest strategy, wind tunnel, drying chamber.

\section{Introduction}

Switchgrass has a wide harvest window and is harvested from late July to February of the following year (Sharma et al., 2011). When harvested at an early maturity stage, switchgrass has a higher moisture of $70 \%$, and it reduces to less than $10 \%$ after the killing frost (Khanchi et al., 2013). Womac et al. (2005) also reported that corn stover, when harvested at early maturity stage, has significantly higher moisture of $34.1 \%$ compared to $15.3 \%$ for late harvest. These crops when harvested early require a field drying period to reduce the moisture to a safe storage level of less than $18 \%$ (Rotz, 1995). The field drying period can vary depending on crop characteristics, environmental conditions and swath structure. As the crop lays in the field, 
32 moisture migration takes place between the crop and the environment, until suitable equilibrium

33 moisture is attained. Field drying time of grasses varies from 2 to 7 days. Drying time is reduced

34 to 2 to 4 days when the grasses are spread in thin layers and weather conditions are favorable

35 (Haghighi, 1990; Moore and Peterson, 1995).

36 Crop characteristics such as yield, stem diameter, leaf to stem ratio, and swath structure can

37 increase or decrease the moisture migration during field drying (Rotz and Shinners, 2007).

38 Density and thickness of the windrow significantly impact the drying rate of the crop in the field.

39 High yield and narrow width results in high-density windrow, which dries slowly compared to a

40 thin and wide swath containing the same amount of biomass (Moore and Peterson, 1995). A

41 thick windrow also blocks the air movement, which carries moisture away from the lower layers

42 to the ambient atmosphere. Freshly harvested biomass is also high in initial moisture and forms a

43 compact windrow that resists the wind penetration. Wind circulation through the windrow can be

44 enhanced by making the windrow more fluffy by raking (Moore and Peterson, 1995).

45 Environmental factors such as solar radiation, wind speed, air temperature, relative humidity, and

46 soil moisture influence the drying behavior of crops in the field. These weather parameters are

47 highly correlated in field conditions and it becomes difficult to analyze the effect of an individual

48 parameter on drying potential of crop (Borreani and Tabacco, 1998). From all the environmental

49 factors solar radiation has the most impact on the drying rate (Bartzanas et al., 2010; Khanchi et

50 al., 2013; Smith, 1990). The impact of wind was also related to solar radiation. It was reported

51 that at high radiation intensity, an increase in wind speed decreases the drying rate of switchgrass

52 (Khanchi et al., 2013) as some of the heat used to enhance the temperature of swath was carried

53 away by the wind. However, at a low radiation intensity, an increase in wind speed improves the

54 drying of switchgrass depending on the vapor pressure deficit (VPD) of the air (Khanchi et al., 
2013). Wright et al. (2000) observed a similar variable effect of wind during drying of rye grass.

They suggested drying the grass in fluffy windrows to improve wind circulation under cloudy conditions.

Some models have been developed that simulate the influence of environment on field drying of crops. The model developed by Womac et al. (2005) estimates the stover moisture content based on days after sowing, soil moisture, rainfall, $\mathrm{RH}$, evapotranspiration, minimum air temperature, soil temperature, and wind speed. The model can predict the moisture content at the end of the day. However, the model developed in the present study can predict hourly as well as daily moisture fluctuation in addition to the moisture content at the end of the day. Shinners et. al. (2007) also evaluated the influence of shredding, swath density and weather conditions on final moisture content of corn stover in Wisconsin, U.S. They found that at an average daily temperature of $5{ }^{\circ} \mathrm{C}$ in mid to late October, only shredded corn stover placed flat in windrows reached safe storage moisture of less than 20\% in 5-7 days. In the second study, none of the treatments reached below $40 \%$ in a 10 day drying period showing the importance of weather conditions in the drying of biomass. In 2003, when the drying conditions were right, the treated stover reached a moisture content of less than $20 \%$ in 4 days. However, when drying was interrupted by rain, none of the treatments reached $20 \%$ after 10 days of drying. Manstretta and Rossi (2015) also developed a model for estimating moisture fluctuation in CS residues as an inoculum source for several fungal pathogens in maize. They used rainfall and VPD to predict the moisture in CS residue after harvest. The model developed in the present study utilizes environmental variables as well as swath density for moisture prediction of CS. Additionally, in other studies (Bartzanas et al., 2010; Khanchi et al., 2013; Smith, 1990) solar radiation was found to be the most important factor affecting the drying of crops in the field. Thus solar 
78 radiation should be included in the models for predicting drying rates of crops in the field

79 conditions.

80 When compared to corn stover, drying studies on switchgrass are more limited. Shinners et. al.

81 (2010) studied field drying rates of switchgrass and reed canary grass. They found that under

82 good drying conditions ( 14 to $30^{\circ} \mathrm{C}$ ) switchgrass dried more quickly when placed in wide swath.

83 In all the cases, the crop was below $20 \%$ moisture in the afternoon of the day after cutting and in

84 some cases reached baling moisture in a single day of drying. Khanchi et. al. (2013) developed

85 an empirical model based on maturity stage and environmental conditions for thin layer drying of

86 switchgrass. However, drying models to predict the drying behavior of switchgrass and corn

87 stover which incorporates swath density are still lacking in the literature. Specific objectives of

88 this present study were to: 1) develop drying models to predict field moisture change of corn

89 stover and switchgrass based on weather conditions, swath density, and maturity stage, 2)

90 evaluate the effect of individual weather parameters and swath density on the drying rate of

91 switchgrass and corn stover, and 3) validate the developed models. The previous design

92 (Khanchi et al., 2013) of the environmental chamber was also improved to reduce the variation

93 or radiation intensity and wind speed in the test section.

\section{2. Material and methods}

\section{$95 \quad 2.1$ Construction of an environmental chamber}

96 The environmental chamber (Fig. 1) was constructed from a wooden framed structure and was

$974.6 \mathrm{~m}$ long and $1.77 \mathrm{~m}$ high. The environmental chamber was divided into a settling section and

98 a test section. The settling section was $1.0 \mathrm{~m}$ high, $1.0 \mathrm{~m}$ wide and $0.85 \mathrm{~m}$ long. The test section

99 was $0.45 \mathrm{~m}$ tall, $0.45 \mathrm{~m}$ wide and $2.0 \mathrm{~m}$ long. There was a transition nozzle in between, which

100 was $0.64 \mathrm{~m}$ long. The dimensions of the settling section and test section were selected to achieve 
101 the desired uniformity and wind speed in the test section where the drying trays were placed for 102 testing. The test section had a door with a plexiglass inspection window for loading and 103 unloading of trays.

\section{$104 \quad 2.2$ Radiation intensity control}

105 Solar radiation was simulated by six equally spaced custom built 500W and 240 Volt quartz

106 radiant heaters. The heaters were fitted in the roof of the test section at the height of $0.46 \mathrm{~m}$. The 107 dimensions of one radiant panel were $0.1 \mathrm{~m}$ by $0.36 \mathrm{~m}$ (MORGQFX10113 Mor Electric Heating 108 Assoc. Inc., MI) and it held a quartz heating element (MORGQQT10305 Mor Electric Heating 109 Assoc. Inc., MI) with an overall length of $0.31 \mathrm{~m}$ and the heating length of $0.2 \mathrm{~m}$. The radiation 110 intensity was controlled by a single solid state power controller (Model no. VHC 32, Fostoria 111 Ind., TN). The radiation intensity was measured by a pyranometer (Model no. LP 02, Hukseflux

112 Thermal Sensors, Netherlands) with a detection range of 285 to $3000 \mathrm{~nm}$. The radiation intensity 113 variation was measured at every $2.5 \mathrm{~cm}$ along the length of the test section. A standard deviation 114 of 19 watt $\mathrm{m}^{-2}$ was observed at a radiation intensity of 410 watt $\mathrm{m}^{-2}$ along the length of the test 115 section. 

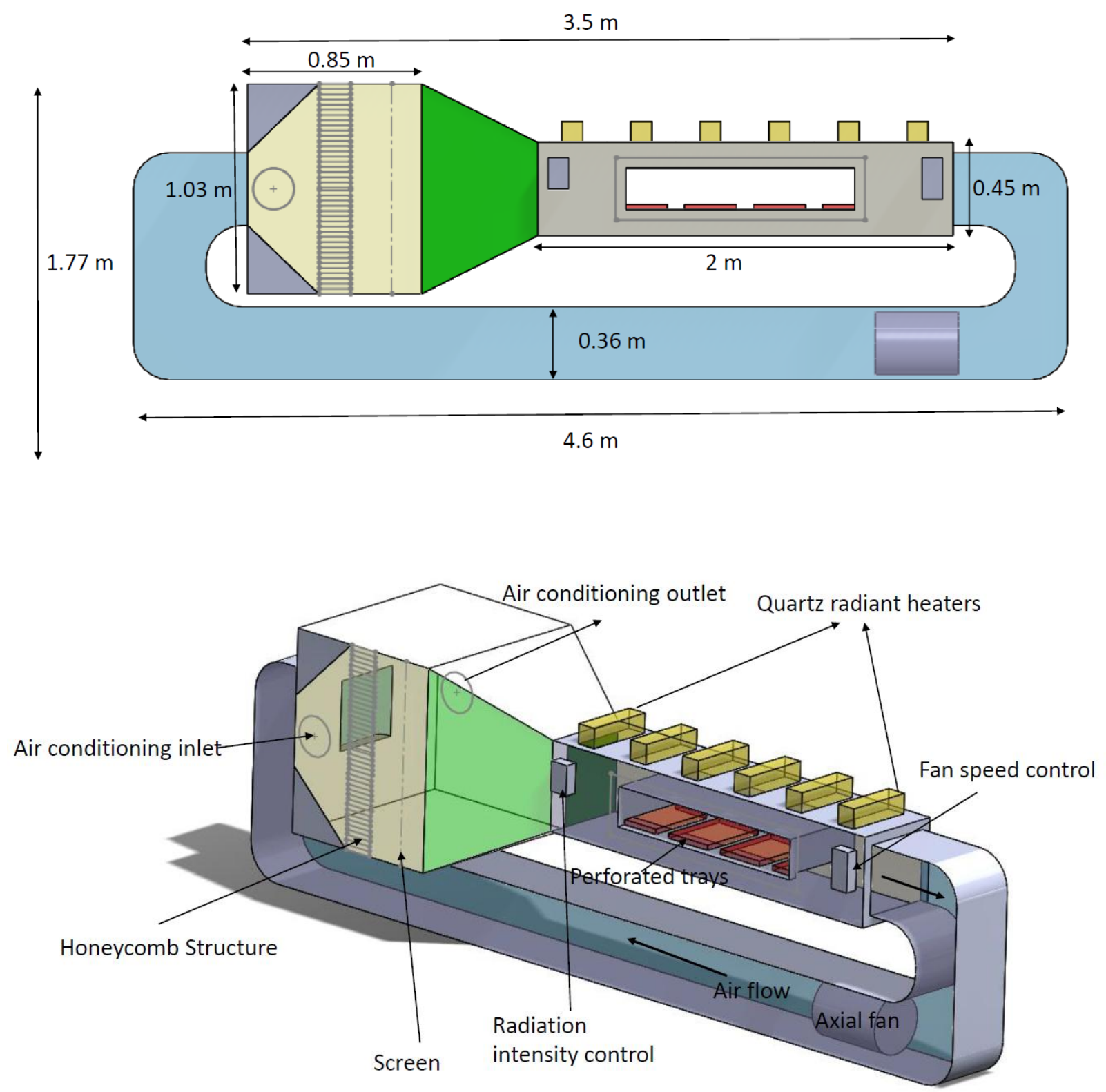

118 Fig 1. Front and side view of environmental chamber

\subsection{Vapor pressure deficit control}

121 Temperature and humidity were controlled by a PGC 400-700 CFM vertical conditioner (Model no. 9240, Parameter Generation and Control, NC). The conditioner unit maintained the air

123 temperature and relative humidity levels within $0.1{ }^{\circ} \mathrm{C}$ and $0.5 \% \mathrm{RH}$, respectively from the set 
124 values in the test section. The inlet and outlet of the conditioner unit were connected to the sides

125 of the settling section before the honeycomb and the screen (Fig 1). The temperature and relative

126 humidity were also recorded at one-minute interval by two temperature and humidity data

127 loggers (Model no. UX 100-011, Onset Computer Corp., MA) placed just before the test section.

128 Vapor pressure deficit (VPD) of air in Pa was calculated by using temperature (T) and humidity

129 (Rh) data in the equation below.

$$
V P D(P a)=\left(1-\frac{R h}{100}\right)\left(6.11 * \exp \left(\frac{17.47 * T}{239+T}\right)\right) * 100
$$

\subsection{Wind speed control}

133 The PGC unit attached to the environmental chamber provided an air flow of $0.25 \mathrm{~m}^{3} \mathrm{~s}^{-1}$ inside

134 the settling section. A 0.31 m diameter and $560 \mathrm{~W}$ axial fan (Model no. D 3702, Sukup

135 Manufacturing Co., IA) controlled by a variable frequency drive (Model no. ATV12H055M2,

136 Schneider Electric, France) were added to the circulation loop of the environmental chamber to

137 change wind speed in the test section. A maximum speed of $5 \mathrm{~m} \mathrm{~s}^{-1}$ was attained at the center of

138 the test section with a variation of $0.3 \mathrm{~m} \mathrm{~s}^{-1}$ along the height of the test section. The axial fan

139 creates lateral mean velocity variation as well as swirls in the air flow which have to be

140 minimized before it reaches the test section. A honeycomb, screens, and transition nozzle were

141 used to improve the flow of air inside the wind tunnel. The details about the functionality and

142 selection criteria of the honeycomb, screens and turning vanes is discussed in detail in the

143 previous study (Khanchi et al., 2013). A honeycomb structure made of PVC tubing having a cell

144 diameter of $0.0254 \mathrm{~m}$ and a length of $0.15 \mathrm{~m}$ was used in the present study. A single screen with

145 a porosity of 0.6 was placed after the honeycomb structure. The transition nozzle placed in

146 between the settling and test section had an area ratio of 5. A typical area ratio of 7 to 12 are used 
147 in low-speed wind tunnel designs but lower and higher values are also common (Barlow et al.,

148 1999). A screen was also installed at the end of the test section to avoid material blowing into the

149 circulating fan. The desired wind speed was set and measured before the start of each experiment

150 by an air flow meter (Model no. 922, Fluke Corporation, WA).

\section{$151 \quad 2.5$ Tray design and automatic weight measurement}

152 The weighing trays were made from galvanized hard cloth with a mesh size of $6.35 \mathrm{~mm}$ to

153 provide adequate ventilation during the drying process. The trays were supported by an

154 aluminum frame structure $(25.4 \mathrm{~mm}$ wide) to provide structural integrity at the bottom. The trays

155 used to simulate different densities had the same surface area but different height. The trays

156 measured $0.36 \mathrm{~m}$ by $0.25 \mathrm{~m}$ in length and breadth, respectively. The height of the tray for low

157 density (LD), medium density (MD) and high density (HD) were 0.1, 0.1, $0.15 \mathrm{~m}$, respectively.

158 At any given time, six trays were randomly placed in the test section with two trays of each LD,

159 MD, and HD. Each tray was kept on a weighing balance (Model no EK-2000i, A\&D Weighing,

160 CA) which was connected to a computer via RS-232 interface and the weight readings were

161 recorded in every 5-minute intervals.

\section{$162 \quad$ 2.6 Selection of weather data for drying experiments}

163 Weather data was collected from July to November for switchgrass during which drying in

164 windrows is required to bring the moisture to a safe storage level. For corn stover harvest, data

165 was collected for the month of September to November. The Iowa Mesonet website (Mesonet,

166 2015) was used to collect the weather data from the year 1986 to 2013 and for 13 weather

167 stations. Daily average values for air temperature $\left({ }^{\circ} \mathrm{C}\right)$, relative humidity $(\%)$, wind speed at $3 \mathrm{~m}$

168 height $\left(\mathrm{m} \mathrm{s}^{-1}\right)$, and solar radiation (Langley) were used to calculate the range of variables tested

169 in the drying study. Wind speed measured at the height of $3 \mathrm{~m}$ will be higher than the wind speed 
170 received by swaths lying close to ground level. Therefore, wind speed data was converted from a

171 height of $3 \mathrm{~m}$ to $0.31 \mathrm{~m}$ elevation by use of the equation below (Chayaprasert and Maier, 2010).

172

$$
U_{h}=U_{r e f}\left(\frac{h}{h_{r e f}}\right)^{a}
$$

173 Where, $U_{h}$ is the local wind velocity measured at height $h(m), U_{\text {ref }}$ is the wind velocity at a

174 reference height $\left(\mathrm{h}_{\text {ref }}\right)$ (example: $\left.3 \mathrm{~m}\right)$, a, the exponent value, 0.14 represents an atmospheric

175 wind boundary layer in open terrain. The calculated wind speed at $0.31 \mathrm{~m}$ height was used to dry

176 switchgrass and corn stover in the environmental chamber. The wind speed was converted again

177 to $2 \mathrm{~m}$ height for model development so that the end user does not have to convert it again during

178 the drying time calculations.

\section{$179 \quad 2.7$ Drying experiments}

180 A representative sample of corn stover was collected from agricultural farms $\left(41^{\circ} 58^{\prime} 37^{\prime \prime} \mathrm{N}\right.$

$18193^{\circ} 46^{\prime} 14^{\prime \prime}$ ) owned by Iowa State University in Boone, IA. Corn stover was collected and

182 packed as round bales after a single pass harvest operation in which corn stover was directly fed

183 into a round baler without making any ground contact. Samples were collected immediately after

184 the harvest by breaking several round bales randomly located in the field. Samples were placed

185 in plastic bags and stored in cold storage at $5{ }^{\circ} \mathrm{C}$ until they were placed in the environmental

186 chamber for drying experiments. Switchgrass samples were manually harvested and collected

187 from research and demonstration farms $\left(41^{\circ} 24^{\prime} 48^{\prime \prime} \mathrm{N} 92^{\circ} 52^{\prime} 10^{\prime \prime} \mathrm{W}\right)$ in Pella, Iowa. The harvested

188 switchgrass was packed in plastic bags and stored in cold storage at $5{ }^{\circ} \mathrm{C}$ until placed in the

189 environmental chamber. The harvesting and sampling schedule is given in Table 1.

Table 1. Harvesting schedule and experiments performed from 2013 to 2015 on corn stover and switchgrass

\begin{tabular}{lll}
\hline Biomass & Corn stover & Switchgrass
\end{tabular}




\begin{tabular}{|c|c|c|}
\hline Harvest date & 17th Aug 2013 & $\begin{array}{c}19^{\text {th }} \text { Oct } 2014,2015\left(6^{\text {th }} \text { Aug, }\right. \\
\left.18^{\text {th }} \text { Sep, } 16^{\text {th }} \text { Oct, } 4^{\text {th }} \text { Nov }\right), 6^{\text {th }} \\
\text { Aug } 2016\end{array}$ \\
\hline Drying experiments performed & 21st Nov 2013 to 11th March 2014 & $\begin{array}{c}10^{\text {th }} \text { Dec } 2014 \text { to } 8^{\text {th }} \text { Jan } \\
2015,7^{\text {th }} \text { Aug } 2015 \text { to } 20^{\text {th }} \text { Jan } \\
2016,9^{\text {th }} \text { Aug to } 19^{\text {th }} \text { Sept } 2016\end{array}$ \\
\hline${ }^{\mathrm{t}}$ Dry density of biomass in trays $\left(\mathrm{kg} \mathrm{m}^{-2}\right)$ & 0.78 (LD), 1.31 (MD), 2.61 (HD) & $\begin{array}{c}0.58(\mathrm{LD}), 1.44(\mathrm{MD}), 2.30 \\
(\mathrm{HD})\end{array}$ \\
\hline
\end{tabular}

1 LD, MD and HD represent low density, medium density and high density trays of biomass.

In the case of corn stover, 60 drying experiments were performed of which 36 (27 day and 9

night) were used in model development and 24 experiments were used for model validation. In

192 the case of switchgrass, 80 experiments were performed in which 72 were used for model

193 development and 8 were used for model validation. For the model development of switchgrass,

19436 (27 day and 9 night) were performed in the seed development stage of maturity and similarly,

19536 were performed in seed shattering and seed shattered stage of maturity. For daytime, a 3 X3X3

196 factorial design was used with three levels of solar radiation, vapor pressure deficit (VPD) and

197 wind speed as the variables (Table 2). For the night, a 3X3 factorial design was used with three

198 levels of VPD and three levels of wind speed. The upper and lower level of weather conditions

199 are based on the extreme weather condition recorded during the harvesting period and the middle

200 value was calculated from the average of the extreme values.

Table 2. Experimental plan for drying of corn stover and switchgrass with environmental conditions tested during the study

\begin{tabular}{lccc}
\hline Crop, Maturity stage, Duration & $\begin{array}{c}\text { Vapor pressure } \\
\text { deficit }(\mathrm{kPa})\end{array}$ & $\begin{array}{c}\text { Solar radiation } \\
\left(\mathrm{W} \mathrm{m}^{-2}\right)\end{array}$ & $\begin{array}{c}\text { Wind speed }\left(\mathrm{m} \mathrm{s}^{-1} \text { at } 2 \mathrm{~m}\right. \\
\text { above ground })\end{array}$ \\
\hline Corn stover (Day) & $1.20,0.85,0.50$ & $400,115,0$ & $5.83,3.25,1.30$ \\
Corn stover (Night) & $1.20,0.85,0.50$ & 0 & $5.83,3.25,1.30$ \\
$\begin{array}{l}\text { Switchgrass, Seed development } \\
\text { Stage (Aug, Sept), Day }\end{array}$ & $2.20,1.40,0.60$ & $450,275,100$ & $5.83,3.25,1.30$ \\
$\begin{array}{l}\text { Switchgrass, Seed development } \\
\text { stage (Aug, Sept), Night }\end{array}$ & $2.00,1.15,0.30$ & 0 & $5.83,3.25,1.30$ \\
$\begin{array}{l}\text { Switchgrass, Seed shattering } \\
\text { (Oct), and seed shattered stage, }\end{array}$ & $1.80,1.10,0.35$ & $400,225,50$ & $5.83,3.25,1.30$
\end{tabular}


Day

Switchgrass, Seed shattering $\quad 2.00,1.13,0.25$

(Oct), and seed shattered (Nov)

stage, Night

202 During each experiment, two trays of each LD, MD and HD were randomly placed in the test

203 section as discussed earlier. Whole switchgrass plant including stems and leaves were cut to fit

204 the dimensions of the tray. No further size reduction was performed on corn stover samples as

205 the highly conditioned samples were easily fitted into the trays. The material density of the

206 samples in the trays for CS and switchgrass is given in Table 1. The switchgrass and CS samples

207 were oriented in a direction perpendicular to the air flow. Before each experiment, CS and

208 switchgrass samples were taken out of cold storage and brought to room temperature. Once the

209 desired conditions of VPD, radiation and wind speed were achieved in the environmental

210 chamber, the samples were filled in the trays and placed on the weighing balances inside the test

211 section. The experiment was stopped when the moisture reached less than $15 \%$ or no change in

212 tray weights were recorded continuously for 5 hours.

213 A drying rate constant was determined for each tray by performing the regression analysis

214 between moisture ratio and drying time data for each tray. Moisture ratio (MR) is given by Eq.

215 (3).

216

$$
M R=\frac{M-M_{e}}{M_{0}-M_{e}}
$$

217 Where, $\mathrm{M}$ is the moisture content at time $\mathrm{t}, \mathrm{M}_{0}$ is the initial moisture content, $\mathrm{M}_{\mathrm{e}}$ is the

218 equilibrium moisture content (EMC). An exponential model was used to fit the moisture ratio

219 data with the time given by Eq. (4). 
221 Where, $\mathrm{k}$ is the drying rate constant $\left(\mathrm{h}^{-1}\right)$ and is obtained by plotting the graph of moisture ratio

222 versus drying time. Since the drying time was recorded in hours, the units of the drying rate 223 constant are given in $\mathrm{h}^{-1}$ in the following sections. For corn stover, $\mathrm{M}_{\mathrm{e}}$ was calculated from the 224 Modified Oswin equation (eq. 5) between the temperature and humidity range of 10 to $40{ }^{\circ} \mathrm{C}$ and 22511 to $98 \%$, respectively, and was given by Igathinathane et al. (2005).

$$
M_{e}=(10.9137-0.0746 * T)\left[\frac{E R h}{1-E R h}\right]^{0.4147}(5)
$$

227 Where, $\mathrm{T}$ is the temperature in ${ }^{\circ} \mathrm{C}$ and $\mathrm{ERh}$ is the equilibrium relative humidity in decimal form. For 228 switchgrass, $\mathrm{M}_{\mathrm{e}}$ was calculated from the Modified Halsey equation (Eq. 6) between the 229 temperature and humidity range of 20 to $40{ }^{\circ} \mathrm{C}$ and 12 to $89 \%$, respectively, and was given by 230 Karunanithy et al. (2013).

$$
M_{e}=\left[\frac{-\exp (15.85-0.0856 * T)}{\ln (E R H)}\right]^{0.186}
$$

232 Additionally, experiments were performed in the environmental chamber to find the $\mathrm{M}_{\mathrm{e}}$ between 233 the temperature and humidity range of 10 to $19{ }^{\circ} \mathrm{C}$ and 55 to $92 \%$, respectively for switchgrass, 234 as it lacked in the literature. Six trays of switchgrass, each weighing $200 \mathrm{~g}$ were kept in the 235 environmental chamber at the desired temperature and humidity and dried until a weight change 236 of less than $0.01 \mathrm{~g}$ was recorded in five hours. After drying in the environmental chamber, the 237 trays were further dried in an oven at $105{ }^{\circ} \mathrm{C}$ for 24 hours to obtain the equilibrium moisture 238 content of the switchgrass samples. The equilibrium moisture content and temperature and 239 humidity data were fitted to the Modified Halsey equation by using the NLIN procedure in SAS 240 9.4 (SAS Institute, 2015) to obtain Eq. 7 below. 


$$
M_{e}=\left[\frac{-\exp (4.9679+0.0201 * T}{\ln (E R H)}\right]^{0.562}
$$

242 The drying rate constant obtained for each tray during the drying experiments was used to

243 develop a regression model that related the drying rate constant with the weather conditions and 244 swath density tested during the experimentation. Regression analysis was completed using Proc 245 Mixed in SAS 9.4 (SAS Institute, 2015).

3. Results

247 3.1 Regression equations to predict moisture content of corn stover and switchgrass

248 During drying, switchgrass and CS followed a falling rate drying period. In this period, the 249 drying rate of crop decreased with time and approached zero as it came in equilibrium with the 250 environment. The exponential drying rate model and regression equations relating the drying rate 251 constant with environmental conditions and swath density are given in Table 3 . The model uses 252 environmental conditions such as hourly radiation, wind speed, VPD and wet crop density to 253 calculate the hourly drying rate of switchgrass and CS. The drying rate, $\mathrm{k}$, is then fitted into the 254 exponential drying model to estimate the moisture content of crop at that time interval. Average 255 daily weather conditions can also be used to assess the moisture content of switchgrass and CS at 256 the end of the day. For CS, models were developed for day and night time conditions. For 257 switchgrass, models were developed for different maturity stages in addition to day and night 258 conditions. These models can predict change in moisture of the crop due to drying and rewetting 259 by dew at night. However, these models cannot predict an increase in moisture due to a rainfall 260 event. Further experimentation is required to estimate the moisture gain after rainfall as well as 261 drying of the crop after the rainfall event. The model was divided into day and night time 262 because the effect of wind speed on drying rate was different in day and night conditions. During 
263 the day, the wind speed was negatively correlated with the drying rate whereas, at night, the

264 wind speed was positively correlated and is explained in the next section.

Table 3. Drying rate model and drying rate constant equation developed for corn stover and switchgrass based on environmental conditions and swath density

\begin{tabular}{|c|c|c|c|c|}
\hline $\begin{array}{l}\text { Time of } \\
\text { the day }\end{array}$ & $\begin{array}{l}\text { Maturity } \\
\text { Stage }\end{array}$ & Drying rate model & Drying rate constant & $\mathrm{R}^{2}$ \\
\hline \multicolumn{5}{|c|}{ Corn Stover } \\
\hline Day & Oct and Nov & $\begin{array}{l}M=M_{e} \\
+\left(M_{0}-M_{e}\right) \\
* \exp (-k * t)\end{array}$ & $\begin{array}{c}k=\exp (-2.5238+0.005564 * \operatorname{Rad}-0.1430 \\
* W S+0.0001081 * V P D-0.2212 \\
* \text { Dens }-0.00074 * \operatorname{Rad} * W S)\end{array}$ & 0.884 \\
\hline Night & Oct and Nov & $\begin{array}{l}M=M_{e} \\
+\left(M_{0}-M_{e}\right) \\
* \exp (-k * t)\end{array}$ & $\begin{array}{c}k=\exp (-3.19+0.001856 * V P D+0.1421 * W S \\
-0.1403 * \text { Dens })\end{array}$ & 0.871 \\
\hline
\end{tabular}

\section{Switchgrass}

\begin{tabular}{|c|c|c|c|c|}
\hline Day & $\begin{array}{l}\text { Aug and } \\
\text { Sept }\end{array}$ & $\begin{array}{l}M=M_{e} \\
+\left(M_{0}-M_{e}\right) \\
* \exp (-k * t)\end{array}$ & $\begin{array}{c}k=\exp (-3.0147+0.002082 * \text { Rad }-0.05172 \\
\quad * W S+0.000192 * V P D-0.1623 \\
\quad * \text { Dens })\end{array}$ & 0.881 \\
\hline NIght & $\begin{array}{l}\text { Aug and } \\
\text { Sept }\end{array}$ & $\begin{array}{l}M=M_{e} \\
+\left(M_{0}-M_{e}\right) \\
* \exp (-k * t)\end{array}$ & $\begin{array}{c}k=\exp (-3.3462+0.03942 * W S+0.000304 \\
* V P D-0.02056 * \text { Dens })\end{array}$ & 0.946 \\
\hline Day & Oct and Nov & $\begin{array}{l}M=M_{e} \\
+\left(M_{0}-M_{e}\right) \\
* \exp (-k * t)\end{array}$ & $\begin{aligned} & k=\exp (-2.6004+0.001539 * \operatorname{Rad}-0.06246 \\
& \\
& \quad * W S+0.000248 * V P D-0.1401 \\
&* \text { Dens })\end{aligned}$ & 0.877 \\
\hline NIght & Oct and Nov & $\begin{array}{l}M=M_{e} \\
+\left(M_{0}-M_{e}\right) \\
* \exp (-k * t)\end{array}$ & $\begin{array}{c}k=\exp (-2.4726-0.02091 * W S+0.000261 \\
* V P D-0.02346 * \text { Dens })\end{array}$ & 0.951 \\
\hline
\end{tabular}

Where, $M$ is the moisture at time $t(\% d b), M_{0}$ is the initial moisture (\% db), $M_{e}$ is the equilibrium moisture $(\% d b)$. For corn stover, Me was calculated by Modified Oswin equation

$M_{e}=(10.9137-0.0746 * T)\left[\frac{E R h}{1-E R h}\right]^{0.4147}$ between the temperature and humidity range of 10 to $40{ }^{\circ} \mathrm{C}$ and 11 to $98 \%$, respectively and was given by Igathinathane et al. (2005). For switchgrass, $\mathrm{M}_{\mathrm{e}}$ was calculated from the Modified Halsey Equation $M_{e}=\left[\frac{-\exp (15.85-0.0856 * T}{\ln (E R H)}\right]^{0.186}$ given by Karunanithy et al (2013) between the temperature range 20 to $40{ }^{\circ} \mathrm{C}$ and $M_{e}=\left[\frac{-\exp (4.9679+0.0201 * T}{\ln (E R H)}\right]^{0.562}$ in the temperature range of 10 to $19{ }^{\circ} \mathrm{C}$. $\mathrm{T}$ is the temperature $\left({ }^{\circ} \mathrm{C}\right)$ and $\mathrm{ERH}$ is the equilibrium relative humidity in decimal, $\mathrm{k}$ is drying rate constant $\left(\mathrm{hr}^{-1}\right), \mathrm{t}$ is the time (hr), Rad is the average radiation intensity for the hour (watt/m $\left.{ }^{2}\right), \mathrm{WS}$ is wind speed (m/s), VPD 
is vapor pressure deficit $(\mathrm{Pa})$ estimated from $\operatorname{VPD}(P a)=\left(1-\frac{R h}{100}\right)\left(6.11 * \exp \left(\frac{17.47 * T}{239+T}\right)\right) * 100$, Dens is the wet swath density $\left(\mathrm{kg} / \mathrm{m}^{2}\right)$

\subsection{Influence of weather conditions and swath density on drying behavior of corn stover} and switchgrass

The coefficient of correlation between drying rate of switchgrass and CS and the variables tested during the study are provided in Table 4. Correlation coefficients for the daytime drying of CS were not presented as an interaction of radiation and wind speed was observed as shown in Table 3 above. Radiation and VPD were found to be the most important factor affecting the drying of

271 these crops during the day and nighttime, respectively.

Table 4 Pearson correlation coefficients between corn stover and switchgrass drying rates and variables tested for different maturity stages in environmental chamber

\begin{tabular}{|c|c|c|c|c|c|}
\hline \multirow[t]{3}{*}{ Variable } & \multicolumn{5}{|c|}{ Correlation coefficients, $r$} \\
\hline & \multirow[t]{2}{*}{ Corn Stover } & \multicolumn{4}{|c|}{ Switchgrass } \\
\hline & & \multicolumn{2}{|c|}{$\begin{array}{l}\text { Seed development stage (Aug., } \\
\text { Sept.) }\end{array}$} & \multicolumn{2}{|c|}{$\begin{array}{c}\text { Seed shattering and seed shatterec } \\
\text { stage (Oct., Nov.) }\end{array}$} \\
\hline $\begin{array}{l}\text { Time of } \\
\text { day }\end{array}$ & Night & Day & Night & Day & Night \\
\hline Radiation & - & $0.50 * *$ & - & $0.49 * *$ & - \\
\hline VPD & $0.69 * *$ & $0.24^{* *}$ & $0.83^{* *}$ & $0.38 * *$ & $0.85^{* *}$ \\
\hline WS & $0.42 * *$ & $-0.20 * *$ & $0.29 * *$ & $-0.36^{* *}$ & -0.22 \\
\hline Density & -0.11 & $-0.38 * *$ & -0.10 & $-0.38 * *$ & -0.13 \\
\hline
\end{tabular}

*Significant at $5 \%$ level, $* *$ Significant at $1 \%$ level

\subsection{Model validation}

274 The developed empirical models were validated by plotting the predicted drying rate of CS and

275 switchgrass as a linear function of experimental drying rate. The experimental drying rates were

276 obtained from experiments performed on randomly selected weather conditions in between the

277 range of weather conditions used for model development given in Table 2. A perfectly fitted model will have a slope of 1.0, intercept of zero and correlation coefficient of 1.0 (Khanchi et al., 
279 2013; Wright et al., 2001). In the present study on corn stover, a correlation of 0.79 was observed 280 with a slope and intercept of 0.7082 and 0.0017 , respectively. Similarly, a correlation coefficient 281 of 0.97 was observed for switchgrass with a slope and intercept of 0.77 and 0.0045 , respectively.

282 The resulted error might have occurred during experimentation or model development in the 283 statistical package. The switchgrass and CS drying rate models were also compared with field 284 drying trials. An example of the model output is presented for switchgrass and CS in Fig 4 and 5, 285 respectively. The plot of field experimental moisture and model predicted moisture did not show 286 any systematic deviations. Most of the predicted moistures for switchgrass and CS were within 287 the standard deviations of the field experimental moisture content, indicating a good fit of the 288 models developed in this study.

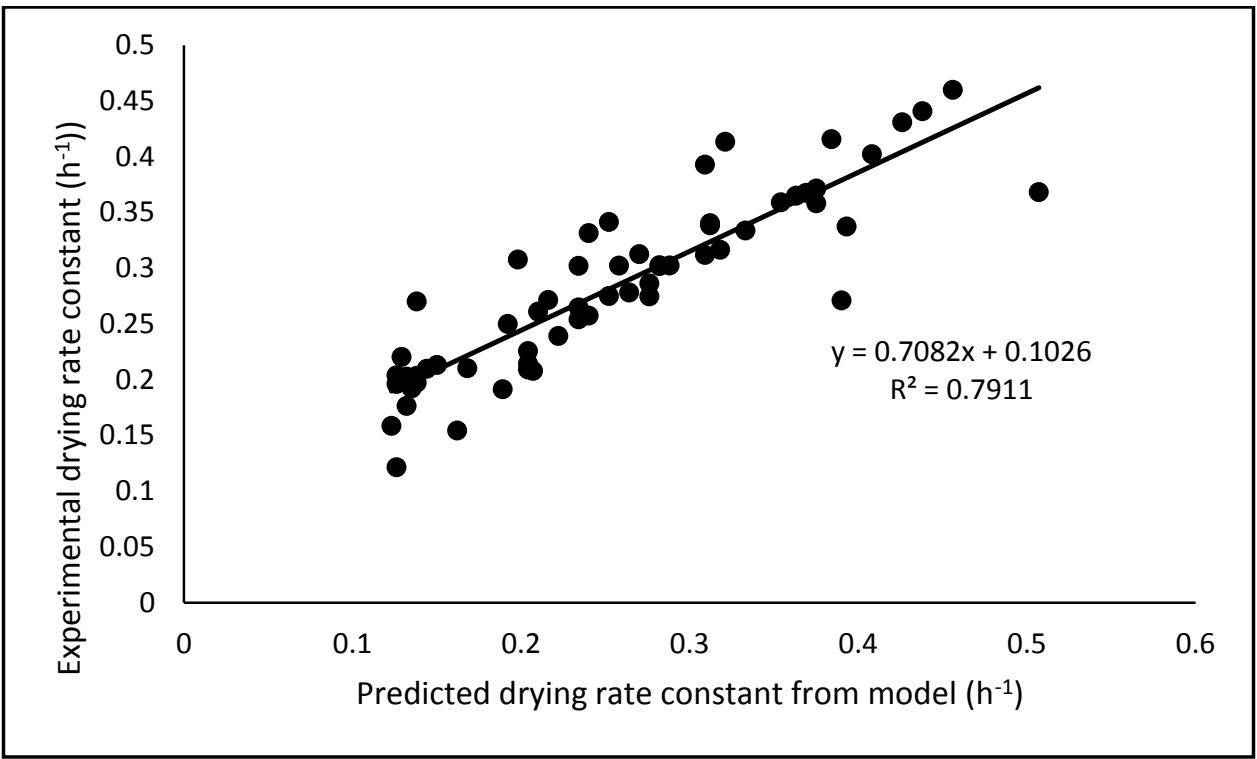

290 Fig 2. A plot of experimental and predicted drying rates of corn stover 


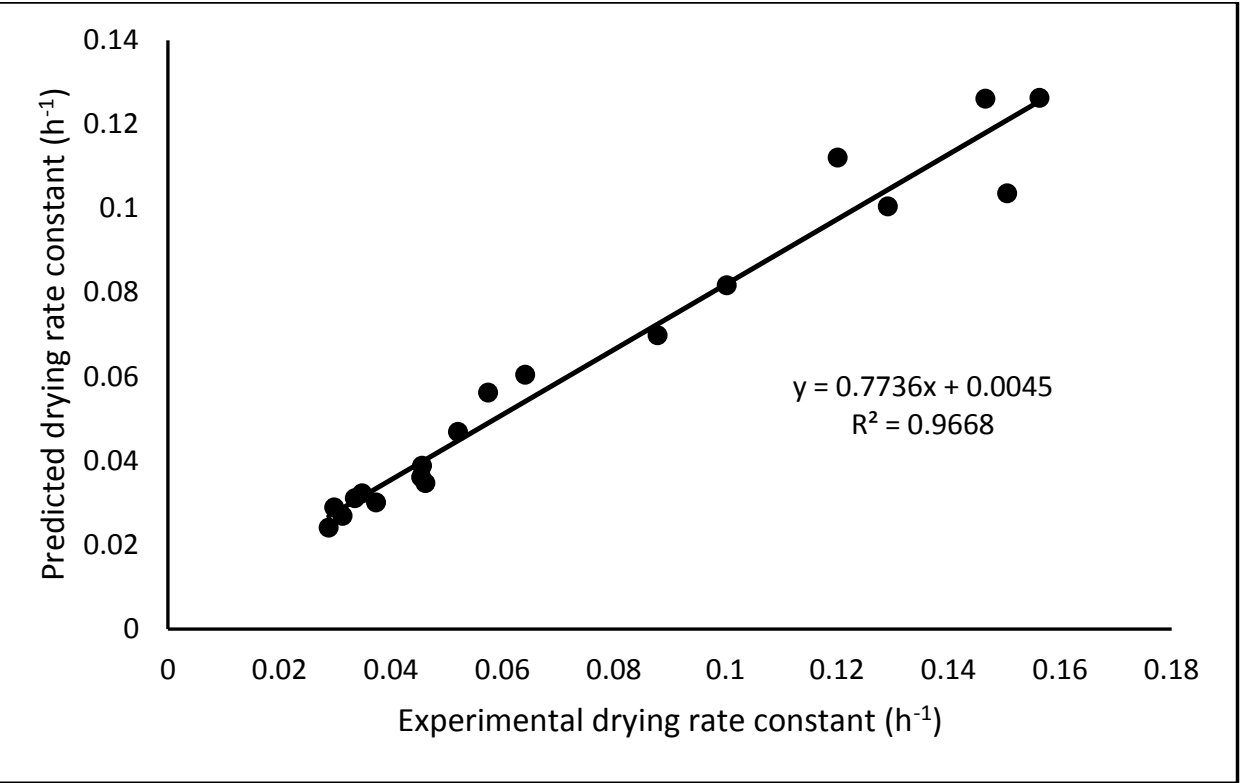

292 Fig 3. A plot of experimental and predicted drying rates of switchgrass

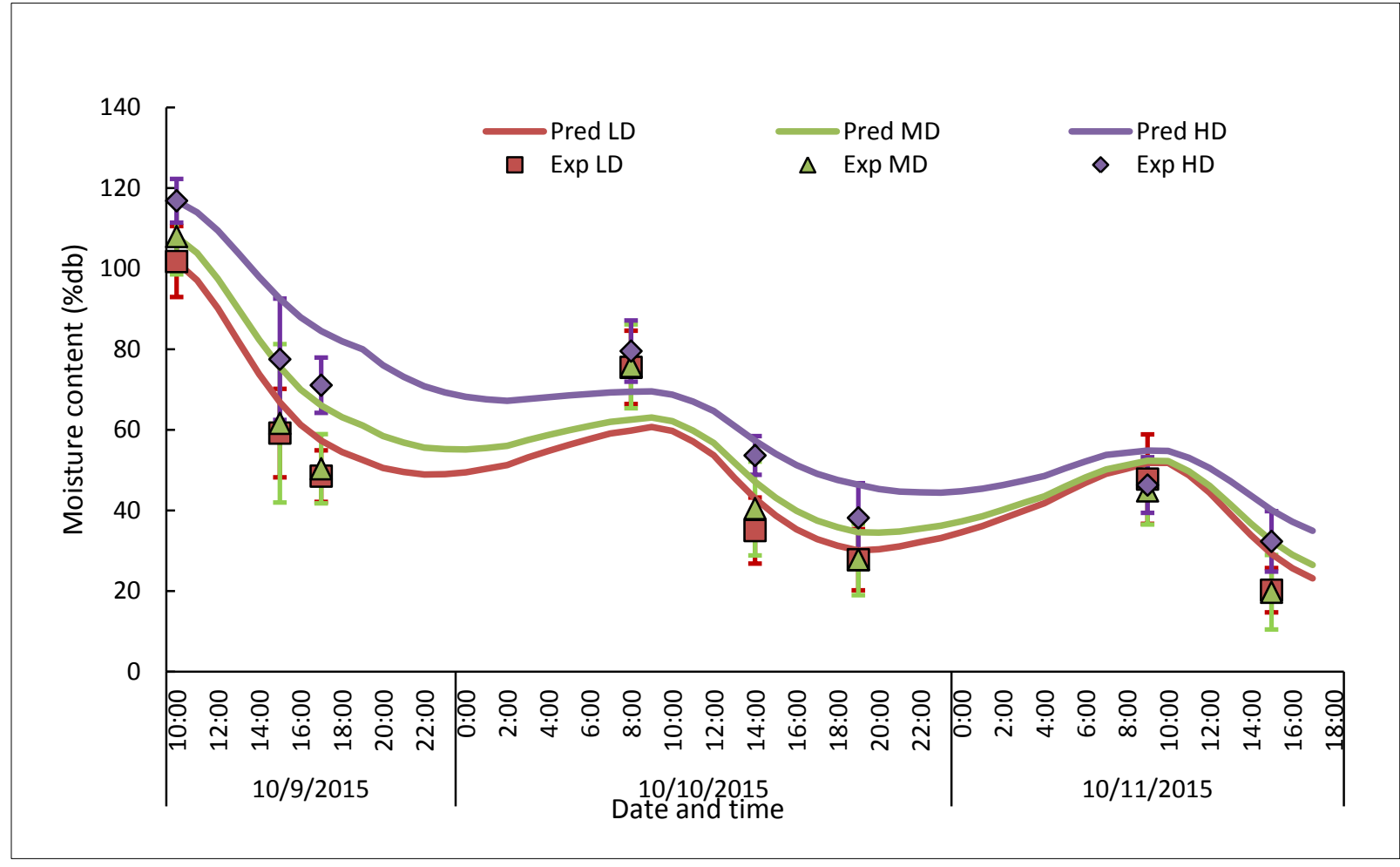

Fig 4. A plot of model predicted and experimental field moisture variation with standard deviation bars for switchgrass. Here, pred, exp, LD, MD, and HD are the abbreviation for 296 predicted, experimental, low density, medium density and, high density, respectively. 


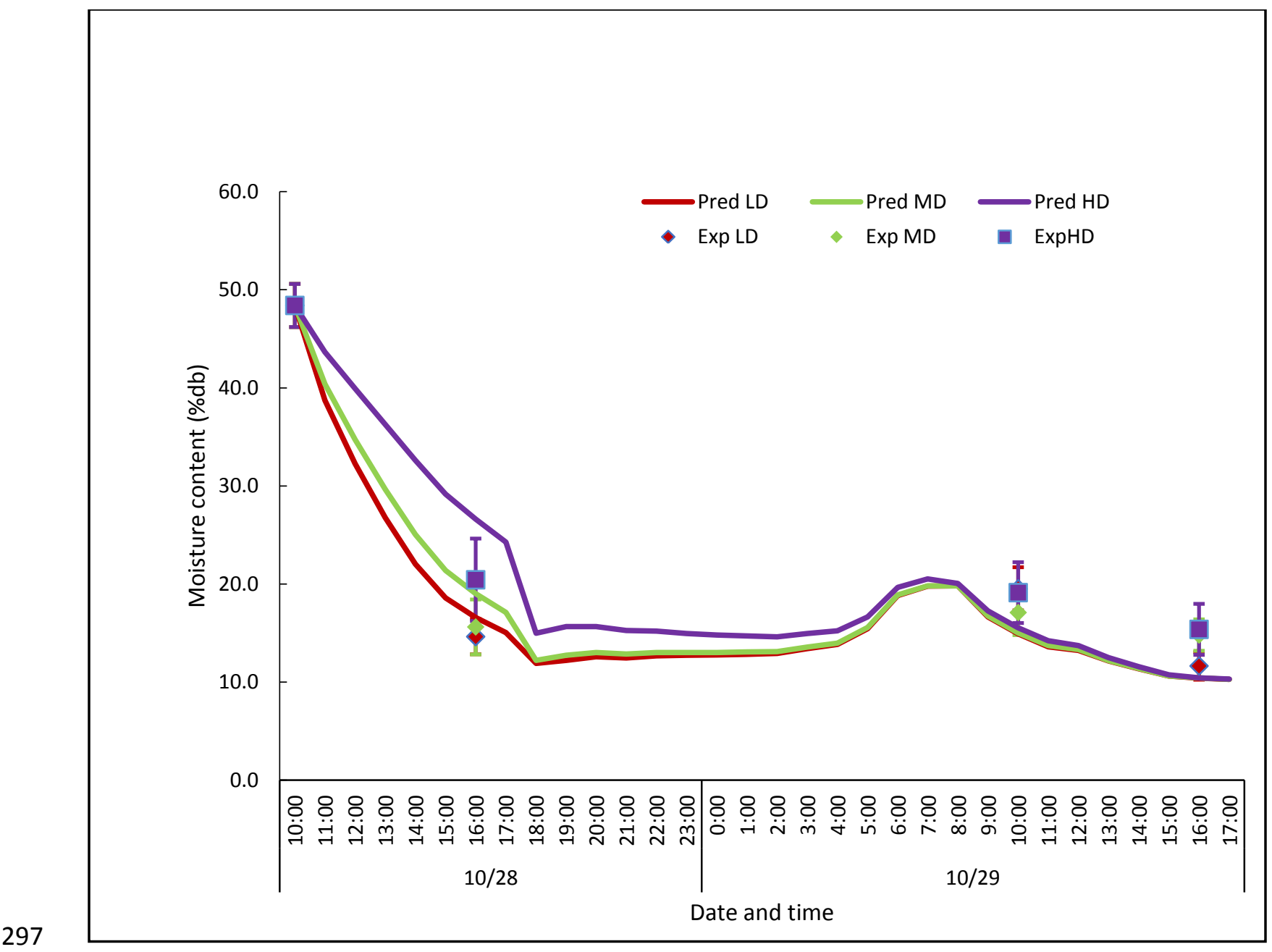

298 Fig 5. A plot of model predicted and experimental field moisture variation with standard 299 deviation bars for corn stover. Here, Pred, Exp, LD, MD, and HD are the abbreviation for 300 predicted, experimental, low density, medium density and, high density, respectively. 


\section{Discussion}

303 Regression models were developed to predict the drying rate of CS and switchgrass based on 304 environmental conditions and swath density. A similar model that can estimate the moisture content of these crops utilizing swath density and time of day is not available in the literature. Models that predict drying rates of switchgrass are also limited and currently no model takes swath density into account while predicting the drying rate of switchgrass. It is important to compare the models developed in lab studies to the field trials to estimate how well they perform in field conditions. In the present study, both field and lab studies were performed and the results of the field drying experiments will be published in future publications.

During the day, radiation and vapor pressure deficit were positively, and swath density and wind

312 speed were negatively correlated with the drying rate of switchgrass. During both maturity stages 313 of switchgrass, radiation was the most important factor influencing the drying rate of switchgrass 314 with a correlation of 0.5 and 0.49 (Table 4). Solar insolation was also found to be the most 315 significant factor by Rotz and Chen (1985) during field drying of alfalfa with a correlation of 0.58 to 0.70 . They reported that solar insolation explained more variation in the drying data than

317 the other combined 13 variables, tested during the study. Wright, Frost, \& Kilpatrick (2000) also observed that radiation was more important than VPD or wind speed in determining grass drying rate as it aids in the removal of internal moisture from the grass plants. Therefore, it is recommended that solar radiation should be included in drying rate models while simulating the

321 field drying behavior of crops. It is also recommended that field operations such as wide swath 322 drying should be implemented to yield the benefit of solar radiation during field drying. High 323 radiation intensity and low wind speed also favored quick drying of switchgrass. In the 324 environmental chamber, when the radiation intensity and VPD were kept constant, an increase in 
325 wind speed decreased the drying rate of switchgrass. The slower drying of switchgrass at higher 326 wind speed could be due to heat loss caused by the wind. The lower temperatures of switchgrass 327 at higher wind speed also indicate that part of the heat generated by radiation was carried away 328 by the wind. VPD was the second most important variable affecting the drying of switchgrass 329 during daytime conditions. A correlation of 0.24 and 0.38 was observed during the different 330 maturity stages of switchgrass. A correlation varying from 0.25 to 0.48 was also observed 331 between VPD and the drying rate of alfalfa during a seven-year field drying study (Rotz and 332 Chen, 1985).

333 At night, VPD and wind speed were positively correlated whereas density was negatively 334 correlated with the drying rate of switchgrass. VPD was the most important variable $(\mathrm{r}=0.83$ to 335 0.85) influencing the drying of switchgrass at night. Contrary to the day time increased wind 336 speed helped in the drying of switchgrass at night. A similar variable effect of wind was also 337 observed by Wright, Frost, \& Kilpatrick (2000) during drying of ryegrass under controlled 338 conditions. They also concluded that when radiation is medium $\left(432 \mathrm{~W} \mathrm{~m}^{-2}\right)$ or high $\left(1081 \mathrm{~W} \mathrm{~m}^{-}\right.$

$339{ }^{2}$ ) the effect of wind is to decrease the drying rate and at night the effect of wind is to increase the 340 drying rates of ryegrass at moderate (10 mbars) or high (16 mbars) VPD. In the present study, 341 the effect of wind speed was not significant during later maturity stages of switchgrass. A 342 possible reason could be the low temperature and high humidity conditions during the night in 343 the month of October and November. No significant improvement in drying rates was observed 344 by increasing the wind speed when the drying conditions were poor (low VPD). In the case of $345 \mathrm{CS}$, the VPD was the most critical factor affecting drying during the night $(\mathrm{r}=0.69)$ and increase 346 in wind speed helped in drying at night. These results suggest that field operations such as raking 347 should be used to make the windrow structure more airy to intersect more wind at night. 
Windrow density was negatively correlated with drying rate of both crops during day and night conditions. For switchgrass, a negative correlation of 0.38 during daytime and 0.1 to 0.13 was observed during the night (Table 4). A negative correlation of 0.15 to 0.20 was also noted by Rotz and Chen (1985) during field drying of alfalfa and concluded that drying rates consistently decreased as swath density was increased.

Models were divided into day and night conditions as the effect of wind was found to be contrary during day and night. An environmental chamber was also designed and fabricated which offered more control on environmental conditions and assisted in evaluating the effect of each variable on the drying rate of switchgrass and CS. The environmental chamber developed in this study can be used to study the drying behavior of other crops and factors which were not covered in this study.

\section{Acknowledgements}

We would like to acknowledge the financial support from the CenUSA Bioenergy project funded by Agriculture and Food Research Initiative Competitive Grant No. 2011-68005-30411 from the USDA National Institute of Food and Agriculture. We would also like to acknowledge the assistance offered by Brian Mc Evoy and Joshua Crouch in the designing of the drying trays and the environmental chamber.

\section{References}

Barlow, J.B., Rae, W.H. and Pope, A., 1999. Low-speed wind tunnel testing. Wiley, New York, pp. 713.

Bartzanas, T., Bochtis, D.D., Sørensen, C.G., Sapounas, A.A. and Green, O., 2010. A numerical modelling approach for biomass field drying. Biosyst. Eng. 106, 458-469.

Borreani, G. and Tabacco, E., 1998. Effects of crop properties, weather conditions and mechanical treatments on the wilting rate of dipliod and tetraploid Italian ryegrass for silage. Grass Forage Sci. 53, 179-188. 
Chayaprasert, W. and Maier, D.E., 2010. Evaluating the effects of sealing quality on gas leakage rates during structural fumigation by pressurization testing and cfd simulations. Trans. ASABE. 53, 9.

Haghighi, K., 1990. Finite element simulation of the thermo-hydro stresses in a viscoelastic sphere during drying. Drying Technol. 8, 466-498.

Igathinathane, C., Womac, A.R., S., S. and Pordesimo, L.O., 2005. Sorption equilibrium moisture characteristics of selected corn stover components. Trans. ASAE. 48, 14491460 .

Karunanithy, C., Muthukumarappan, K. and Donepudi, A., 2013. Moisture sorption characteristics of switchgrass and prairie cord grass. Fuel, 103, 171-178.

Khanchi, A. et al., 2013. An empirical model to predict infield thin layer drying rate of cut switchgrass. Biomass Bioenerg. 58, 128-135.

Manstretta, V. and Rossi, V., 2015. Modelling the effect of weather on moisture fluctuations in maize stalk residues, an important inoculum source for plant diseases. Agric. For. Meteorol. 207, 83-93.

Mesonet, I., 2015. ISU agclimate/ legacy network daily download/ Daily data resquest form. http://mesonet.agron.iastate.edu/agclimate/hist/dailyRequest.php.

Moore, K.J. and Peterson, M.A., 1995. Post-harvest physiology and preservation of forages., American Society of Agronomy, Crop Science Society of America. CSSA Special Publication Madison, Wisconsin, pp. 39-66.

Rotz, C.A., 1995. Field curing of forages, in: K.J. Moore and M.A. Peterson (Editors), Postharvest physiology and preservation of forages. CSSA Special Publication, Madison, WI, pp. 39-66.

Rotz, C.A. and Chen, Y., 1985. Alfalfa drying model for the field environment. Trans. ASAE. 28, 1686-1691.

Rotz, C.A. and Shinners, K.J., 2007. Hay harvest and storage, in: Barnes, R.F., Nelson, C. J. Moore, K.J, Collins, M. (Eds.), Forages: The science of grassland agriculture. Blackwell Publishing, Ames, IA, pp. 601-616.

SAS Institute, 2015. Cary, NC, USA.

Sharma, B., Jones, C.L. and Khanchi, A., 2011. Tensile strength and shear strength of switchgrass before and after frost. Biol. Eng. 4, 43-54.

Shinners, K.J., Binversie, B.N., Muck, R.E. and Weimer, P.J., 2007. Comparison of wet and dry corn stover harvest and storage. Biomass Bioenerg. 31, 211-221.

Shinners, K.J., Boettcher, G.C., Muck, R.E., Weimer, P.J. and Casler, M.D., 2010. Harvest and storage of two perennial grasses as biomass feedstocks. Trans. ASABE. 53, 359-370.

Smith, E.A., 1990. A review on field drying of grass. Drying Technology, 8(3): 465-498.

Womac, A.R., Igathinathane, C., Sokhansanj, S. and Pordesimo, L.O., 2005. Biomass moisture relations of an agricultural field residue: corn stover. Trans. ASAE. 48, 2073-2083.

Wright, D.A., Frost, J.P. and Kilpatrick, D.J., 2000. The influence of weather factors on the drying rate of cut perennial ryegrass herbage under controlled conditions. Grass Forage 
414 Wright, D.A., Frost, J.P., Patterson, D.C. and Kilpatrick, D.J., 2001. PA--Precision Agriculture:

415 Development of a Model to predict Drying Rates of Cut Ryegrass. J. Agric. Eng. Res. 79, 23-35. 